Bull. Mater. Scı., Vol. o, No. ', September 1984, pp. 901-922. (C) Printed in India.

\title{
Growth of research and development in rare metals extraction in India
}

\author{
C V SUNDARAM and C K GUPTA* \\ Reactor Research Centre, Kalpakkam 603 102, India \\ * Extractive Metallurgy Section, Bhabha Atomic Research Centre, Trombay, Bombay 400085 , \\ India
}

\begin{abstract}
The ushering in of the era of high technology in our country witnessed the emergence and growth of several new technologies which are either totally unconventional or less common in otherwise well known and established areas of industrial practice. A vivid example of the second category of advances is found in the development of extractive processes for obtaining the less common metals particularly required for service in nuclear, aerospace and electronics industries. In this paper, the growth of research and development in rare metals extraction in India is surveyed from its infancy in the fifties to the present stature of a firm tooted technology accredited with several directed achievements and well-developed maturity.
\end{abstract}

Keywords. Rare metal extraction; physical beneficiation; chemical beneficiation; breakdown process; separation process; halide metallurgy; electrolytic reduction.

\section{Introduction}

One of the greatest technological upheavals in the history of human civilization was triggered by the second world war. During the post war period a large spectrum of high technology industries flourished. The frontiers of established technologies expanded and new highways opened up in the hitherto unexplored regions. The march of human progress entered into what is variously referred to as the nuclear age, the space age and the electronics age.

If one looks at the mainstream technologies which defined the direction and sustained the momentum of such a total technological advance, achievements in metals and materials development stand out, having played a vital role. The development of appropriate metals and materials has always been crucial to transform scientific ideas into practical realities.

We witness today, in our country, wide-ranging activities in the fields of science and technology. Since independence, we have come a long way in securing such an expansion. It is a matter of pride that we observe in the national scene massive development programmes in a number of advancing technological areas, as for instance, in nuclear energy, aeronautics and aerospace, electronics and oceanography - thanks to the efforts made and the support given to usher in this new era.

Tracing back the sequence of science and technology development, it would seem to have started with the launching of the atomic energy programme in the country. Following the institution of the Atomic Energy Commission (AEC) and the modest beginnings made in the early fifties, many disciplines of science and engineering - of relevance to this programme- have evolved and flourished. The wide variety and scope in these disciplines have enabled the progressive transfer of the experience to other 
areas of science and technology. Developments in space, aeronautics and electronics have gradually entered the national scene.

Any discussion on technological growth has to lead a discussion on materials development which constitutes the supporting structure like a back bone. As indicated in figure 1, while many of the ferrous and non-ferrous metals that are in every day use, are also required for peripheral structural applications in modern technology, they are not adequate for the critical core component applications in these technologies. Several members of the rare metals group viz beryllium, titanium, zirconium, hafnium, vanadium, niobium, tantalum, thorium, uranium, plutonium and the rare earths, possess the unique combination of physicomechanical, nuclear, electronic, and chemical properties. Taken together, these characteristics have qualified many of the above mentioned metals for core component applications.

The extractive processes to obtain this specific family of metals indigenously at sufficient purity levels and in adequate quantities were not initially available. The development programme of $\mathrm{AEC}$, however, proceeded on the basic assumption that as it progresses, an adequate, dependable and continuing supply of appropriate metals and materials will be assured. To relieve the dependence on overseas sources for the strategic materials and to keep scientific and technological progress from being impeded or slowed down by materials shortages, pursuits on metals and materials development received close attention. It is needless to mention here that without a strong and sound materials base, it is difficult to attain, in the long run, technological self-sufficiency, particularly in the frontier areas.

India is fortunately blessed with significant raw material reserves with respect to many of the strategic metals. Complete and proper utilization of our natural rare metal resources presupposes the availability of a comprehensive body of scientific knowledge and engineering experience in the field of metal processing. An organization with multidisciplinary resources and skill to support a large spectrum of research projects in virtually all phases of metallurgy (figure 2) could accomplish this feat. This responsibility was thus taken over by the various laboratory and industrial units of the Department of Atomic Energy and, in particular, by the Bhabha Atomic Research Centre (BARC). "Growth of R \& D in rare metal extraction in India" then predominantly

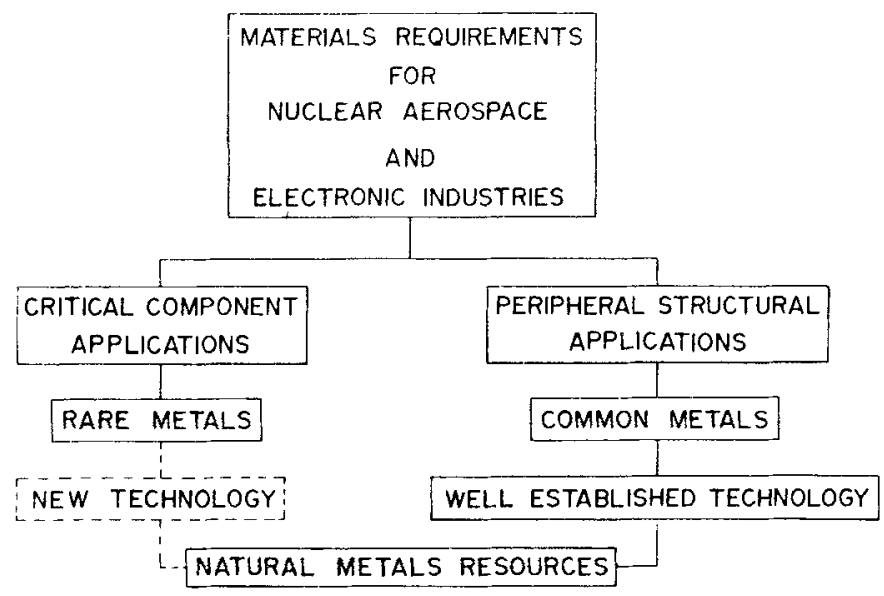

Figure 1. Status of materials requirement in high technologies. 


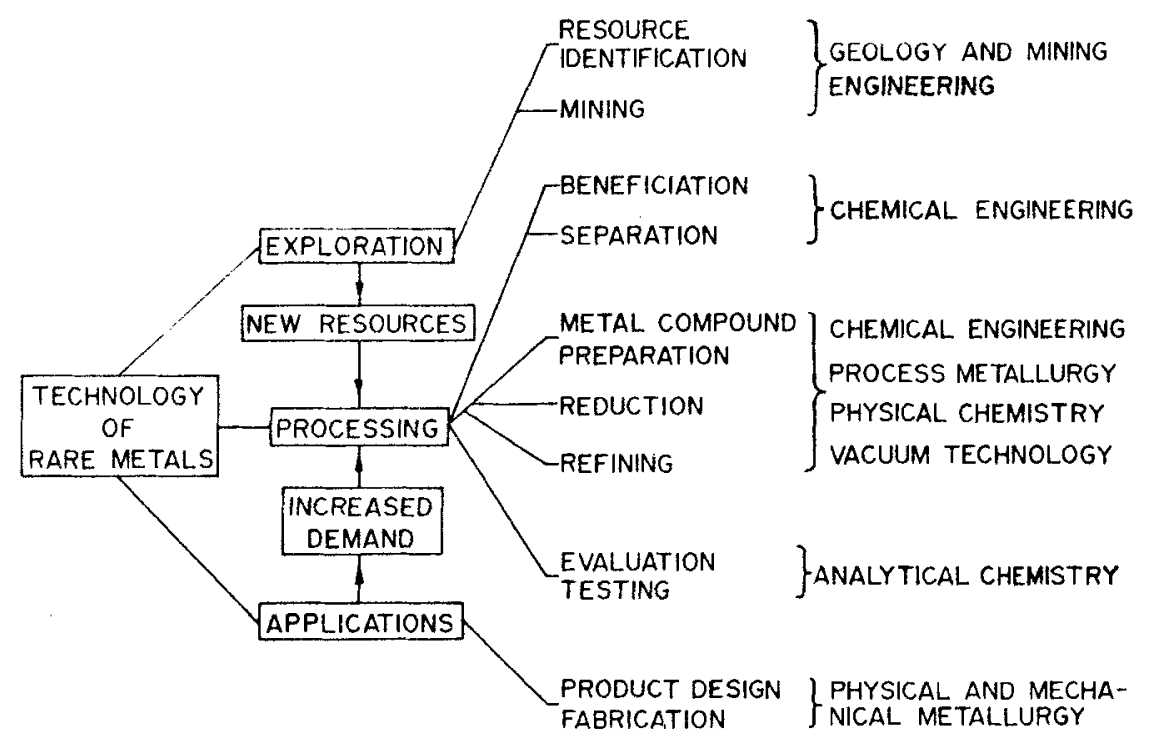

Figure 2. Multidisciplinary content of rare metal extraction.

pertains to tracing the process metallurgy activities of the DAE family during the past three decades.

\section{Definition of rare metals extraction}

Extractive metallurgy consists of the science and art of winning metals from the mined ore. For most common metals, the extractive metallurgy means the sequence of roasting, smelting and refining operations as indicated in figure 3 . This scheme has characteristically failed to work in the extraction of many of the rare metals with which this presentation is concerned. Rare metals occur in nature in very complex forms, often in very low concentration. The procedures involved for recovering metal values are very elaborate, complex and require special equipment, processes and skill. Further, these metals show a high degree of sensitivity to impurities, which influence pronouncedly their physical, chemical and metallurgical properties. This dictates that the rare metals be properly protected at every stage of their production and use.

Broadly, the process sequence for rare metals, as indicated in figure 3 consists of the all important separation step followed by specialised reduction and refining operations. As a further elaboration, figure 4 presents a generalised scheme for rare metal extraction. For an appreciation of such a sequence, a brief reference may be drawn to the extractive metallurgy of niobium, the flow sheet for which appears in figure 5.

The joint occurrence of niobium and tantalum in nature conditioned by their close chemical similarities and the difficulties in separating them from each other halted their industrial development. In the past three decades, with substantial growth in demand and also in technology, complete flowsheets have been developed to get the pure metals in sufficient quantities.

The beneficiated columbite-tantalite ore is fed to the separation step. A pyrovacuum method was first attempted to separate the metals by chlorination but a hydro- 


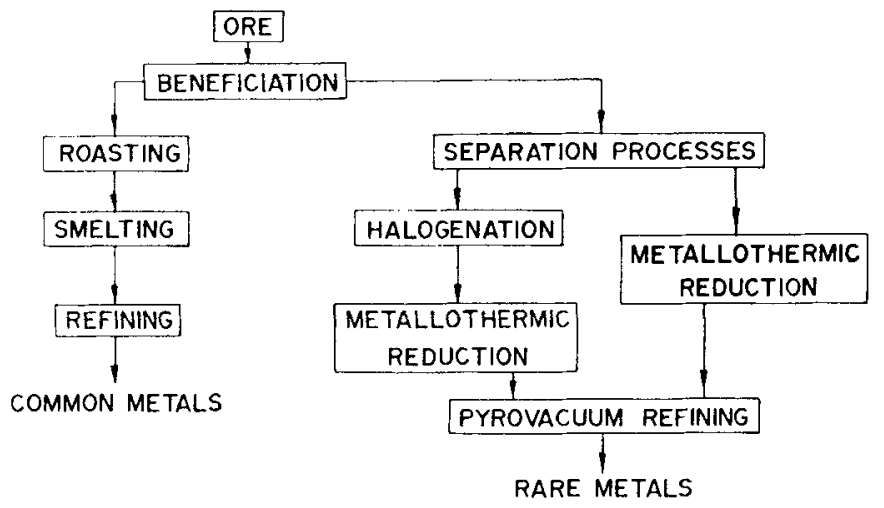

Figure 3. Extraction sequences for common and uncommon metals.

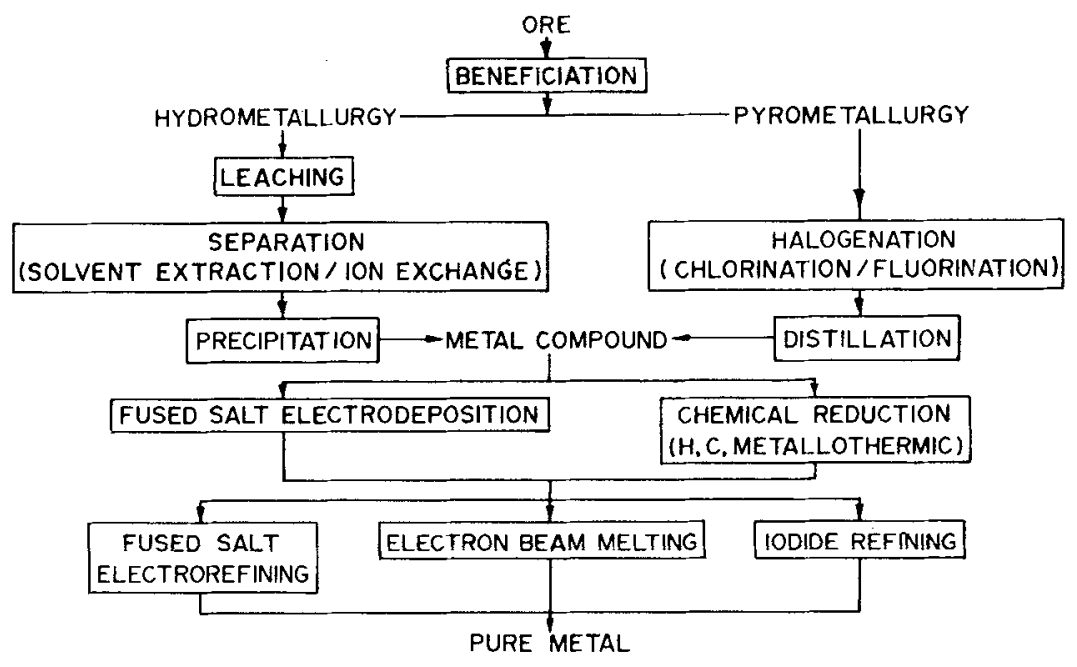

Figure 4. Generalised scheme for rare metal extraction.

metallurgical route involving solvent extraction of the fluoride leach liquor of the beneficiated columbite-tantalite found industrial acceptance sooner. Pure niobium pentoxide obtained after the separation step is converted to the metal by either carbothermic reduction at high temperatures under vacuum or aluminothermic reduction and pyrovacuum refining. Depending on the purity desired, primary niobium is subjected to electron beam melt refining/electron beam floating zone refining to obtain the final product.

Now one can see the path niobium ore travels before it becomes metal. It may be added here that niobium is a well-behaved member of the rare metal family, and in many cases we may have to encounter tougher reactive rare metals.

\section{Indian experience in rare metal extraction}

The Indian experience in rare metal extraction has been founded on a commitment to provide means by which the current and emerging demands for special metals and 


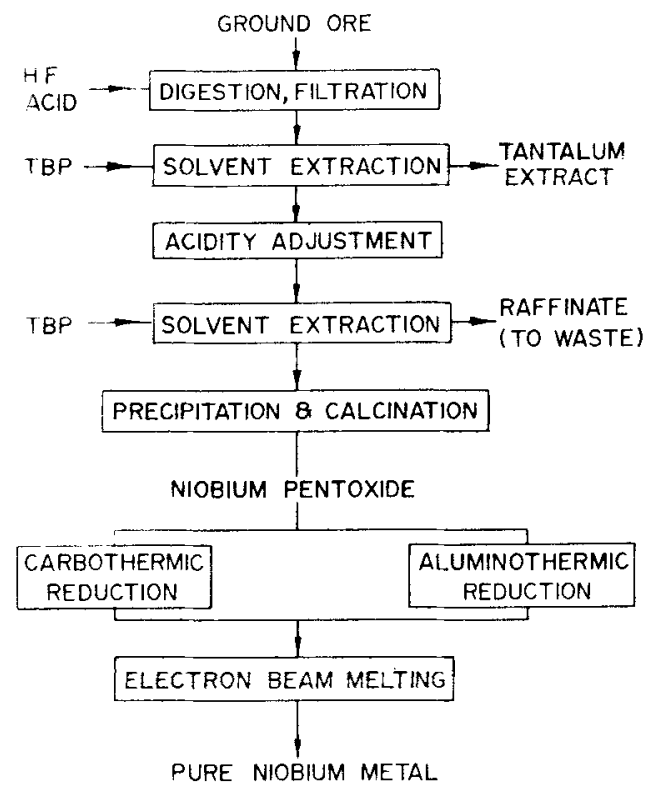

Figure 5. Flow sheet for niobium extraction.

materials in our country could be met. The emphasis has been on developing techniques effective on our indigenous resources. It is needless to say that this development of technology being totally indigenous, we encountered several teething troubles with respect to some processing steps due to scale up which were successfully overcome by persistent efforts. Every effort was made to introduce indigenous equipment which posed considerable problems and cost considerable time. Based on the research and development work at BARC administered mainly under the metallurgy, chemical engineering and chemistry groups, techniques and processes have been successfully evolved and developed to levels conducive to setting up of production plants. By way of some typical examples, mention may be made of:

-uranium oxide and metal production, involving ore leaching, ion exchange, solvent extraction, calcination, hydrofluorination and chemical reduction, induction melting, high temperature sintering and further fabrication;

- zirconium metal production by alkali fusion of zircon, solvent extraction, calcination, chlorination, magnesium reduction and vacuum distillation, vacuum arc melting, extrusion and pilgering;

- tantalum metal production by hydrofluoric acid dissolution of columbite-tantalite, solvent extraction, sodium reduction, powder metallurgy and electron beam melting;

- beryllium metal production by silicofluoride sintering of beryl, leaching, purification, fluoride decomposition, magnesium reduction, vacuum melting and vacuum hot pressing.

The experience has led to the setting up of the Nuclear Fuel Complex (NFC) at Hyderabad which for the past ten years has been engaged in the production of a range of nucler and special materials. Based on the parallel investigation on titanium sponge production and pilot plant demonstration at NFC, a larger production plant for the 
metal is under establishment at the Defence Metallurgical Research Laboratory (DMRL), Hyderabad. The pilot plant for beryllium, set up at Vashi, New Bombay has commenced operation.

Starting off from this introductory indication of the scope and level of directed R \& D efforts that have gone into the emergence and rise of India in the rare metals field in the world, it is now appropriate to proceed a coverage of the Indian experience in more representative detail by looking at each of the unit operations in turn.

\section{Physical beneficiation}

It is a characteristic of all the rare metal resources that they occur as dilute, multicomponent complex minerals widely dispersed and distributed in various geological formations. Development of beneficiating techniques for these ores has, in fact, grown into a technology of lean ore beneficiation. This technology has also aided in many instances in the beneficiation of lean and complex common metal resources also.

In table 1 are listed the main rare metals minerals occurring in our country. Besides there are at least twice as many secondary minerals for each of these metals. There are then the second line reserves to be prospected. The principal beneficiating methods which are at our disposal are indicated in figure 6. One or more of these methods in combination have been employed for beneficiation. It is instructive to briefly review the processes applied to the important resources of many rare metals, beach sands.

Table 1. Important rare metal resources

\begin{tabular}{|c|c|c|c|}
\hline Metal & Mineral & Composition & Location \\
\hline Th & Monazite & $(\mathrm{Ce}, \mathrm{Y}, \mathrm{Ca}, \mathrm{Th}) \mathrm{PO}_{4}$ & $\begin{array}{l}\text { Beach sands of Kerala, Orissa, Andhra } \\
\text { Pradesh, Tamil Nadu }\end{array}$ \\
\hline $\mathrm{Zr}$ & Zircon & $\mathrm{ZrSiO}_{4}$ & Beach sands \\
\hline $\mathrm{Ti}$ & $\begin{array}{l}\text { Ilmenite } \\
\text { Rutile }\end{array}$ & $\begin{array}{l}\mathrm{FeTiO}_{3} \\
\mathrm{TiO}_{2}\end{array}$ & Beach sands \\
\hline \multirow[t]{2}{*}{$\mathrm{Nb}$} & $\begin{array}{l}\text { Columbite } \\
\text { Pyrochlore }\end{array}$ & $\begin{array}{l}(\mathrm{Fe}, \mathrm{Mn}) \mathrm{Nb}_{2} \mathrm{O}_{6} \\
(\mathrm{Na}, \mathrm{Ca})_{2} \mathrm{Nb}_{2} \mathrm{O}_{6}(\mathrm{OH}, \mathrm{F})\end{array}$ & $\begin{array}{l}\text { Hazaribagh, Monghyr (Bihar) } \\
\text { Dharmapuri Dist (TN), Khammam (AP), } \\
\text { Gujarat, Bhilwada Dist (Rajasthan) }\end{array}$ \\
\hline & Samarskite & $(\mathrm{Fe}, \mathrm{Y}, \mathrm{U})_{2}(\mathrm{Nb}, \mathrm{Ti}, \mathrm{Ta})_{2} \mathrm{O}_{7}$ & $\begin{array}{l}\text { Pegmatites of Hazaribagh, Nellore, Jaipur } \\
\text { and Tonk Dist of Rajasthan }\end{array}$ \\
\hline $\mathrm{Ta}$ & $\begin{array}{l}\text { Tantalite } \\
\text { Microlite }\end{array}$ & $\begin{array}{l}(\mathrm{Fe}, \mathrm{Mn})(\mathrm{Ta}, \mathrm{Nb})_{2} \mathrm{O}_{6} \\
(\mathrm{Ca}, \mathrm{Na})_{2} \mathrm{Ta}_{2} \mathrm{O}_{6}(\mathrm{O}, \mathrm{OH}, \mathrm{F})\end{array}$ & $\begin{array}{l}\text { Hazaribagh, Monghyr (Bihar) } \\
\text { Hazaribagh, Monghyr (Bihar) }\end{array}$ \\
\hline $\mathrm{Be}$ & $\begin{array}{l}\text { Beryl } \\
\text { (aquamarine, } \\
\text { emerald, } \\
\text { heliodro, } \\
\text { morganite) }\end{array}$ & $\mathrm{Al}_{2} \mathrm{Be}_{3}\left(\mathrm{Si}_{6} \mathrm{O}_{18}\right)$ & Bihar, Rajasthan, AP, MP., \\
\hline $\mathbf{U}$ & $\begin{array}{l}\text { Uraninite } \\
\text { Pitchblende }\end{array}$ & $\begin{array}{l}\left(\mathrm{U}_{1-x}^{+4} \mathrm{U}_{x}^{+6}\right) \mathrm{O}_{2+x} \\
\text { Variety of uraninite }\end{array}$ & $\begin{array}{l}\text { Jaduguda, Singhbhum (Bihar) } \\
\text { South Kanara (Karnataka) }\end{array}$ \\
\hline
\end{tabular}




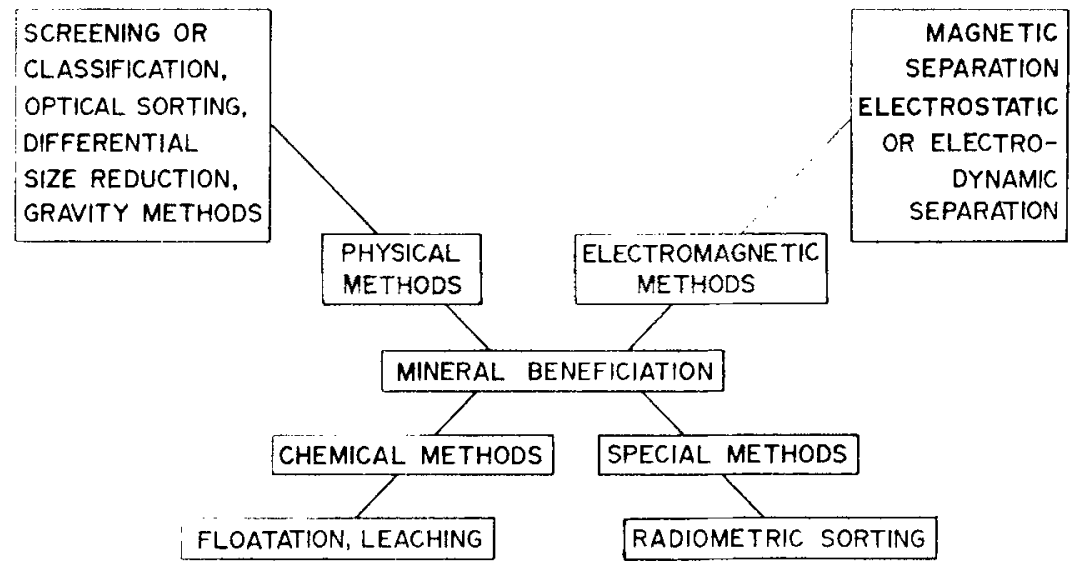

Figure 6. Beneficiation techniques for rare metals resources.

I'able 2. Typical mincral composition of monazite sands

\begin{tabular}{lc}
\hline Constituent & Percent \\
\hline Monazite & $0 \cdot 5-1$ \\
IImenite & $65-80$ \\
Rutile & $3-6$ \\
Zircon & $4-6$ \\
Sillimanite & $2-5$ \\
iarnet & $1-5$ \\
\hline
\end{tabular}

The commonly occurring minerals in beach sand deposits are ilmenite, rutile, zircon, monazite, sillimanite and garnet. Table 2 gives the typical mineral composition of the beach sands. The beach sand minerals occur extensively but in small concentrations in the alluvial deposits. The sand is mined by suction dredging and subjected to preconcentration with a view to obtain a bulk gravity concentrate comprising the heavy minerals. The lean sand deposit containing $2-5 \%$ heavy minerals is subjected to concentration using pinched sluices, cone concentrators, spirals and wet tables to obtain a concentrate with more than $80 \%$ heavy minerals. The separation of individual minerals is carried out by dry methods. Almost all the principal mineral dressing methods viz screening, gravity separation, magnetic separation, electrostatic separation, froth flotation etc are employed in the recovery of economic minerals from beach sand deposits.

Monozite, ilmenite, rutile and zircon are classified as scheduled minerals according to the Atomic Energy Act of 1962. Indian Rare Earths Limited operates three beneficiating plants--two at Manavala Kurichi in Tamil Nadu and one at Chavara, Kerala. Another plant is operated by Kerala Minerals and Metals Limited. At present the country's entire need of beach sand minerals is being met by IRE and KMM. Extensive dense sand deposits along the south Orissa coast over a stretch of $150 \mathrm{~km}$ has been located by Atomic Minerals Division and unlike the existing dry mill beneficiating operations, the Chatrapur operation would include a wet plant also for exploiting the Orissa deposit. 


\section{Chemical beneficiation and breakdown processes}

The tenor of the uranium ores - uraninite, pitch blends, brannerite, uranothorite and carnotite - exploited for metal production assays usually around $0.05-0 \cdot 2 \% \mathrm{U}_{3} \mathrm{O}_{8}$. These low grade ores are directly leached to extract the uranium values since most of the physical beneficiation techniques have not been found economically feasible. There are many methods and techniques in leaching. Ore characteristics, material handling problems, methods employed for metal recovery from the pregnant solution, tailings disposal and many other factors determine the leaching technique.

Except in the case of high grade uranium ores or ores with a high concentration of acid consuming minerals which will necessitate alkali leaching with sodium carbonate, acid leaching with sulphuric acid is particularly suited to the dissolution of uranium values from the ore. As only hexavalent uranium is soluble in aqueous solution, the leaching is performed in the presence of an oxidising agent such as $\mathrm{MnO}_{2}, \mathrm{NaClO}_{3}$ and $\mathrm{Fe}_{2}\left(\mathrm{SO}_{4}\right)_{3}$. Acid concentration and $\mathrm{pH}$ are the two important process parameters. In the case of ores containing uraninite and pitchblende, such as the one at Jaduguda, acid concentration is normally controlled by maintaining $\mathrm{pH}$ of 1.5 to 2 . This type of leaching, under controlled $\mathrm{pH}$ conditions helps in preventing the dissolution of acid consuming minerals like spatite. It has been found that high concentration of phosphate in the solution influences the oxidation potentials and complicates the uranium recovery process.

Besides aqueous leaching, chemical breakdown processes involve digestion with acid or alkali solution or more drastic fusion with alkali and alkali fluorides. The major breakdown processes commonly employed in our country to solubilize the metal values are schematically outlined in figure 7 . It is understood that, as broadly presented for uranium, several parameters require control for accomplishing successful breakdown operation. The beryl ore is opened up to yield water soluble $\mathrm{Na}_{2} \mathrm{BeF}_{4}$ by fusing it with sodium silicofluoride and sodium carbonate at $700^{\circ} \mathrm{C}$.

Having seen so far the established and commercially operating breakdown processes, we can briefly digress to see the direction for new developments.

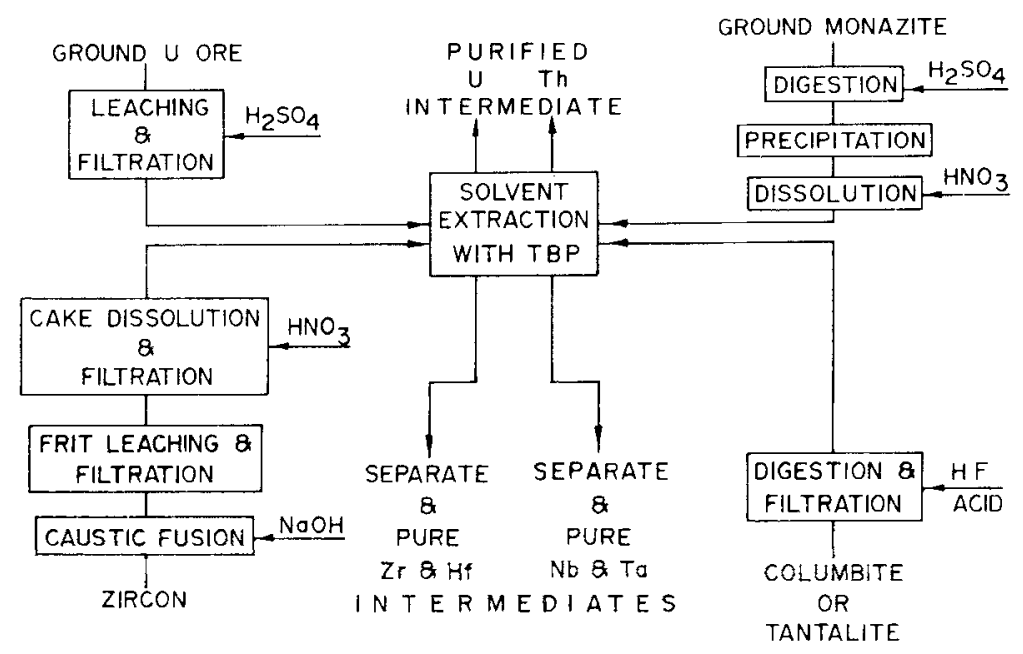

Figure 7. Schematics of ore treatment processes prior to solvent extraction separation. 
A powerful new leaching technique is pressure leaching. Complex minerals like ilmenite and pyrochlore can be transformed into relatively pure oxides in a single step by treatment with hydrochloric acid at high temperature and pressure in an autoclave. References abound evidencing application of pressure leaching to many other minerals including those of uranium. A new approach to leaching low grade uranium ores is provided by the so-called bacterial or microbial leaching. Certain types of autotropic bacteria of the thiobacillus-ferrobacillus group act on the sulphate minerals like pyrite and lead to generation of ferric sulphate and sulphuric acid to leach out uranium.

Other breakdown methods developed to various levels of advancement include soda ash sintering of zircon, electrothermal smelting of ilmenite, beneficiation of ilmenite and zircon in plasma furnaces and chlorination breakdown of ores.

\section{Separation processes}

The leach solution obtained by chemical breakdown of the beneficiated ore is passsd through some unique sequence of "purification" operations peculiar to rare metal extraction. This purification of the pregnant rare metal solution is essentially to separate the co-occurring elements from the desired metal before it is put through subsequent reduction and refining operations. It must be emphasised that the elements co-occurring with the rare metals if allowed to proceed through the reduction step normally cannot be removed from the reduced primary metal by any of the common post reduction refining. This situation may be thought of as arising due to the great reactivity of the rare metals in general. A great deal of effort has gone into the development of separation processes for the purification of uranium and thorium to nuclear grades of purity, separation of rare earth metals from one another, niobium from tantalum and zirconium from hafnium. Of the many alternatives explored and studied at Trombay, two major processes have emerged for effective plant level utilization-solvent extraction and ion exchange.

In solvent extraction, the purification is achieved by selective extraction of compounds of a given element or impurities from aqueous solutions into an organic solvent which is immiscible with water. This is possible when the distribution coefficients of the components in the mixture differ from each other sufficiently. The distribution coefficient which is the crucial parameter in solvent extraction depends on the properties of the solvent, the concentration of the extracted species in the aqueous phase, the presence of other species in the solution, the acidity of the aqueous phase and the temperature. The studies conducted at Trombay were directed not only at optimising these conditions but also obtaining the engineering details such as selection of suitable solvent, collection of equilibrium data, determination of stages, mass transfer rates, choice of contacting equipment and scale-up.

A typical extraction flowsheet is given in figure 8. Starting from its application for recovering uranium from ore leach liquors, solvent extraction has grown in diversity and some of the important systems are presented in table 3. Solvent extraction is practised on a plant scale in our department for the extraction of uranium, thorium, plutonium and for the separation of zirconium from hafnium and niobium from tantalum starting from a variety of aqueous feed solutions using TBP as the organic phase and mixer settlers for contacting equipment.

Ion exchange has been the specialist separation process for use with very dilute feed 


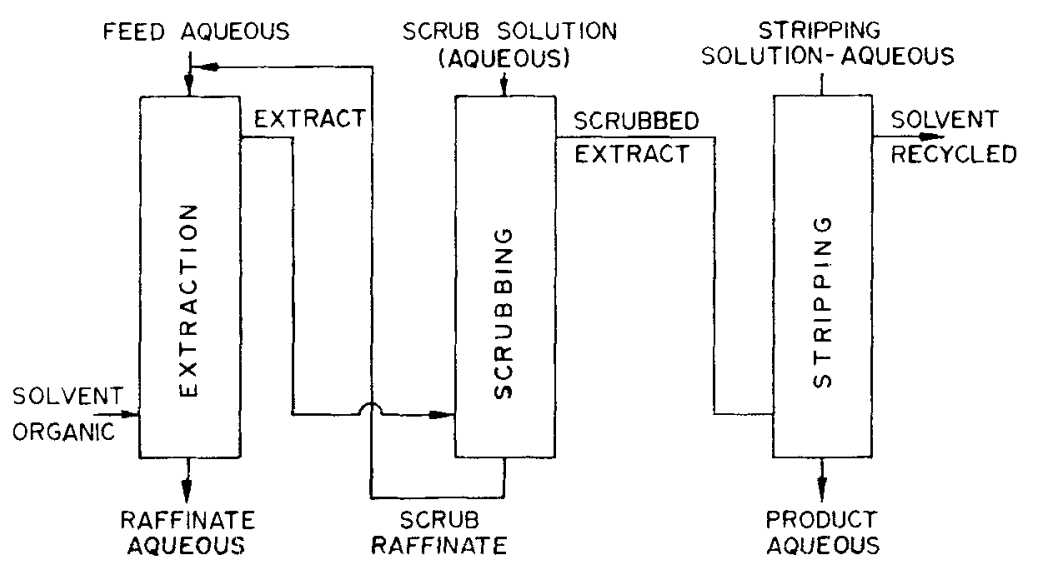

Figure 8. Typical solvent extraction flowsheet.

Table 3. Solvent extraction for separation for purification of rare metals

\begin{tabular}{|c|c|c|c|}
\hline Metal & $\begin{array}{c}\text { Organic } \\
\text { phase }\end{array}$ & $\begin{array}{l}\text { Aqueous } \\
\text { solution }\end{array}$ & Remarks \\
\hline $\mathrm{U}$ & TBP & Nitrate & Purification of $U$ to nuclear grade \\
\hline$T h$ & TBP & Nitrate & Purification of $T h$ to nuclear grade \\
\hline $\mathrm{Zr}$ & TBP & Nitrate & Separation from $\mathrm{Hf}$ \\
\hline $\mathrm{Ta}$ & TBP & Fluoride & Separation from $\mathrm{Nb}$ \\
\hline Lanthanides & DEHPA & Chloride & Separation of individual lanthanides \\
\hline
\end{tabular}

solutions. The most spectacular application of ion exchange has been in the recovery of uranium from low grade ore leach liquors. It is especially better than solvent extraction in such cases.

Ion exchangers are sparingly soluble solids (organic or inorganic) with active functional groups which can be exchanged for ions present in the solution. The schematics of the ion exchange operation is given in figure 9. As the affinity of the ion exchange resin depends on the charge and size of the ionic species involved in the exchange and the distribution coefficient varies with the conditions of the aqueous phase like acidity etc, selective separation and purification can be achieved. Ion exchange separations are generally slow and operate on much less throughputs compared to solvent extraction processes. However as indicated already, for dilute solutions, in cases where separation factors are close and in some cases for processing unclarified solutions ion exchange is particularly sought after. Some important systems processed by ion exchange are given in table 4 .

\section{Halide metallurgy}

The separation steps generally give the pure products in the form of either oxides or halides. These metal compound intermediates are converted to the metal by various reduction processes. Here again, peculiar for rare metals, one encounters a unique 

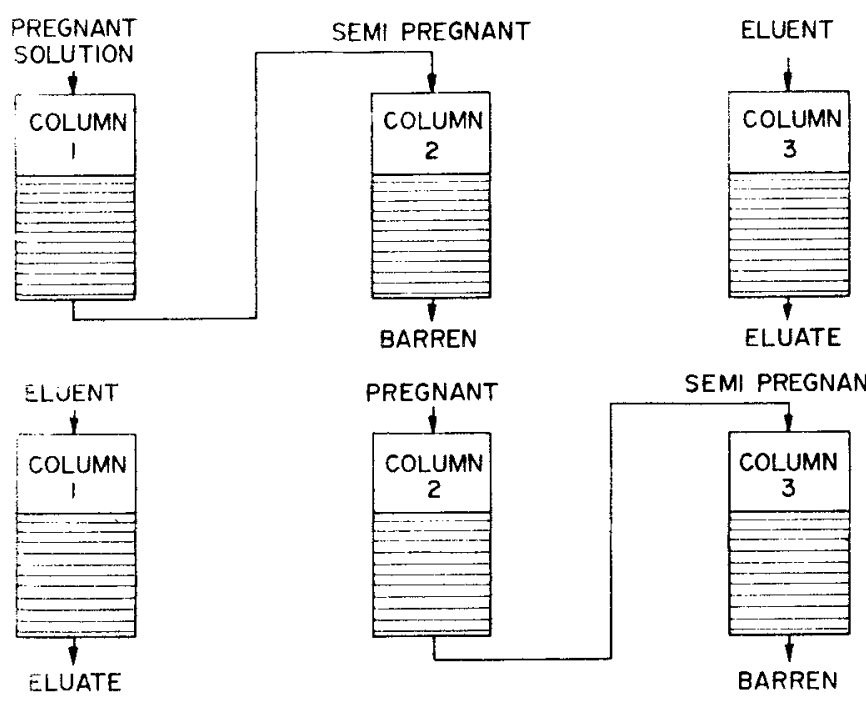

SEMI PREGNANT

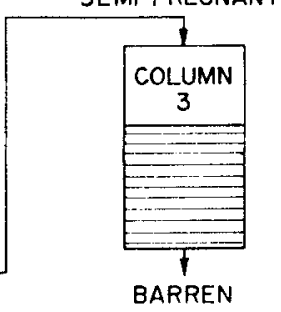

Figure 9. Ion exchange--adsorption, elution flow-sheet.

Table 4. Ion exchange separation for purification of rare metals

\begin{tabular}{|c|c|c|c|}
\hline Metal & Ion Exchanger & Aqueous feed & Remarks \\
\hline $\mathbf{U}$ & Deacidite FF(530) & Sulphate & $\begin{array}{l}\text { Uranium separated from elements } \\
\text { co-occurring in the ore }\end{array}$ \\
\hline $\mathrm{Zr}$ & Cation exchanger ZK-225 & Nitrate & $\mathrm{Zr}$ is separated from $\mathrm{Hf}$ \\
\hline $\mathrm{Ta}$ & Anion exchanger EDE-10P & Fluoride & $\mathrm{Ta}$ is separated from $\mathrm{Nb}$ \\
\hline $\begin{array}{l}\text { Rare } \\
\text { earths }\end{array}$ & $\begin{array}{l}\text { Cation exchanger } \\
\text { Dowex } 50, \mathrm{ZK} 225\end{array}$ & Chloride & $\begin{array}{l}\text { Rare earth metals are separated from } \\
\text { each other }\end{array}$ \\
\hline
\end{tabular}

system of metal production. The intermediate which is reduced to obtain the metal is invariably a halide. The involvement of halides in rare metals ex traction is certainly not restricted to the reduction step. Its omnipresent close involvement at many other stages of metal extraction also shall be looked into in what follows.

Halogens and halides find application in almost all stages of rare metal extraction from ore beneficiation to metal purification as given in figure 10. The diversity of halide metallurgy can be gauged from the following examples. (i) Ore breakdown: chlorination of zircon, ilmenite, rutile, silicofluoride treatment of beryl, zircon; (ii) Halogenation of crude intermediate: chlorination of zirconium carbide; (iii) Halogenation of pure intermediate: chlorination of zirconium dioxide, titanium dioxide; hydrofluorination of uranium dioxide; (iv) Reduction of metal halides: sodium reduction of $\mathrm{K}_{2} \mathrm{TaF}_{7}$, calcium reduction of $\mathrm{UF}_{4}$ magnesium reduction of $\mathrm{TiCl}_{4}, \mathrm{ZrCl}_{4}$, $\mathrm{BeF}_{2}$, electrolysis of RE chlorides; (v) Reclamation of scrap: by chlorination and fused salt electrorefining; (vi) Ultrapurification of commercial grade metal: iodide process for crystal bar titanium, zirconium and hafnium.

Starting with the gas-solid reactions, to carry out the entire range of processes as 


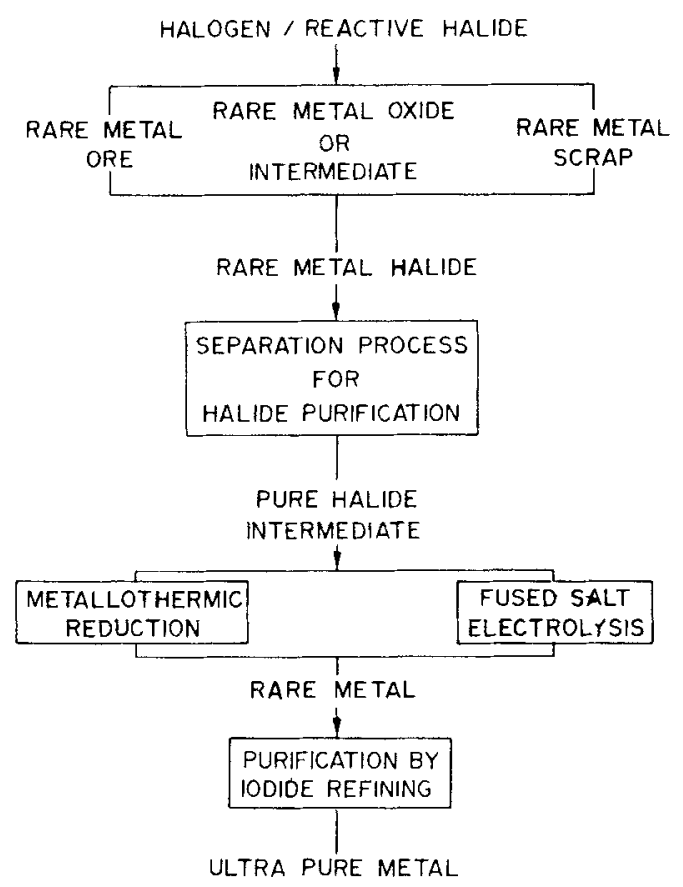

Figure 10. Halogenation in rare metal extraction.

indicated above, a large variety of reactors have been developed and process optimised at Trombay and later transferred to the industrial units of the Department.

The high temperature of these reactions and the corrosive nature of the halogen and the halide vapours, restrict the choice of the material of construction and the type of equipment for large scale operation. While nickel is compatible with fluorine and fluoride vapours upto $800^{\circ} \mathrm{C}$, nickel and inconel alloys can withstand chlorine upto $600^{\circ} \mathrm{C}$. In the production of $\mathrm{ZrCl}_{4}$ or $\mathrm{TiCl}_{4}$ that involves temperatures of $700-900^{\circ} \mathrm{C}$, one has to use quartz or silica in the reaction zone.

Further, a halogenation plant will also include provision for safe metering of the corrosive halogens and the safe disposal of the unreacted halogens by neutralising with alkali or otherwise, due to high toxicity.

At Trombay, a rotating magnesium-tube lined reactor is employed for the production of $\mathrm{UF}_{4}$ by the hydrofluorination of $\mathrm{UO}_{2}$ powder. A special constructional feature of the reactor is that it has two concentric tubes with the annular space filled with an inert seal gas. The inside tube is made of magnesium to withstand the corrosive action of hydrofluoric acid, while steel is chosen for the outer tube for ease of fabrication and strength. The leak tightness of the seals between the rotating tube and the stationary end parts of the furnace is obtained by adopting the principle of positive gas pressure seal between teflon inner sealing rings and outer rubber sealing rings. The reactor is held in a slightly inclined position to facilitate smooth flow of $\mathrm{UO}_{2}$ powder fed through a screw conveyor.

As a further example, one can look at the chlorinator used for the production of zirconium and titanium chloride.

The feed for static bed chlorinators consists of a mixture of oxide and carbon 
preformed into briquettes. The green briquettes are dried and coked at $800^{\circ} \mathrm{C}$ in inert nitrogen atmosphere to obtain highly porous briquettes for efficient chlorination. The large scale chlorination is carried out in a high purity silica brick lined furnace. The briquettes are heated by impressing three phase voltage across three graphite electrodes embedded in the charge. The carbonised briquettes possess sufficient electrical conductivity which improves with temperature, and with appropriate voltage and current control, the charge is slowly heated to the reaction temperature of $700-900^{\circ} \mathrm{C}$. $\mathrm{ZrCl}_{4}$ vapours evolving from the chlorinator furnace are condensed in a double walled inconel condenser at $150-200^{\circ} \mathrm{C}$ as dense crystals suitable for metal production. Blocking is a common problem in chlorinators. Hence pressure monitoring gauges, pressure release discs, and clearance ports have to be provided at critical locations.

Most of the chlorination reactions are exothermic in nature and require close control of temperature which is better achieved in fluidised bed reactors. These reactors also offer advantages like excellent gas-solid contact, good heat transfer, relatively inexpensive reactors and easier start-up and shutdown operations. Systems for the multistage fluidised bed hydrofluorination of $\mathrm{UO}_{2}$ and the fluidised bed chlorination of zircaloy scrap in an inert bed have been developed at this Department.

The volatility of halides, the facility for purifying these by distillation and possibility of reducing these halides with metals like magnesium, sodium, and calcium have provided a powerful means for the production of reactive metals.

\section{Metal reduction processes}

The reduction of rare metal starts either from a halide or an oxide and follows the route as given in figures 11 and 12 .

A majority of the rare metals have been produced by reducing their halides. The reason may either be that it is not possible to reduce the oxide directly at all (e.g. Ti, U, $\mathrm{Be}$ ) or that it is more convenient to reduce the halide (e.g. $\mathrm{Zr}, \mathrm{Hf}, \mathrm{Ta}, \mathrm{Th})$.

\section{Reduction of halides}

The reduction of halides is accomplished by using the metals, sodium, magnesium or calcium as the reducing agent. Depending upon the physical properties of the reactants

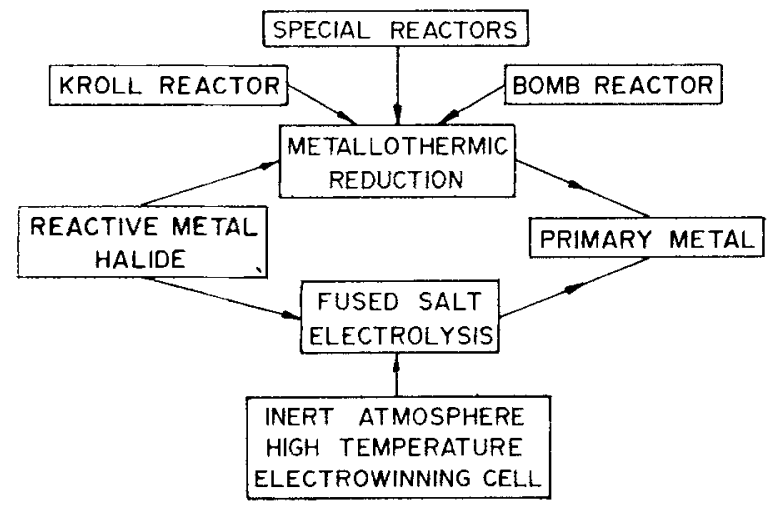

Figure 11. Reduction of rare metals--halide toute. 


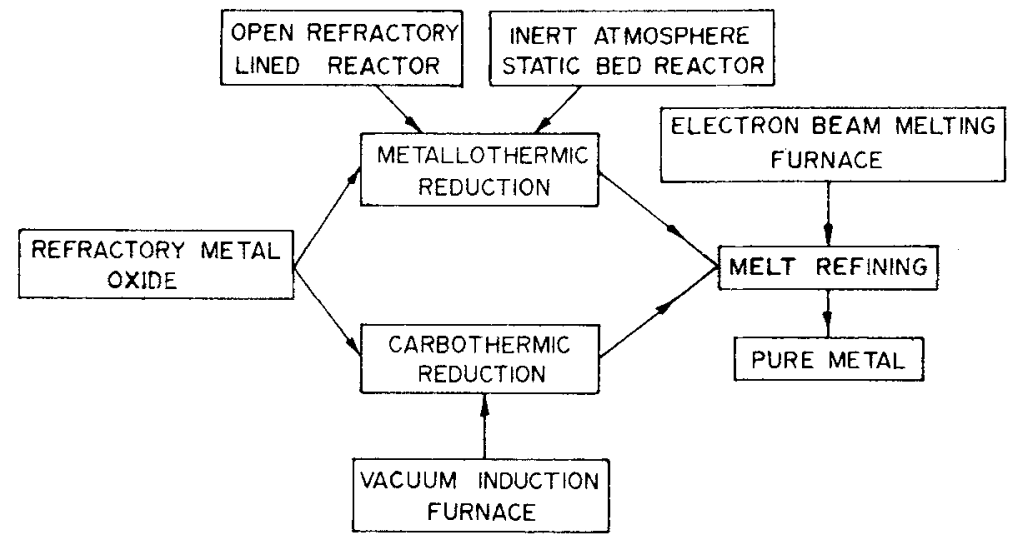

Figure 12. Reduction of rare metals-oxide route.

and products and the heat of reaction, the product metal is recovered as an ingot ( $U$, $\mathrm{Th}$ ), sponge ( $\mathrm{Zr}, \mathrm{Ti}$ ) or powder ( $\mathrm{Ta}$ ). The reduction processes developed for $\mathrm{U}, \mathrm{Th}, \mathrm{Zr}$, $\mathrm{Ti}$, Ta and $\mathrm{Be}$ in fact provide fine examples of process metallurgy of fluorides and chlorides realised on an industrial scale for the production purposes. The exothermic metal reduction processes fall under two major categories-adiabatic (thermit type) and isothermal (Kroll type). Calciothermic reduction of uranium tetrafluoride is a fine example of the thermit type reaction. The uranium metal plant at Trombay has been producing consistently and efficiently uranium metal by the calciothermic reduction route.

In the Trombay practice, high purity $\mathrm{UF}_{4}$ powder is intimately mixed with calcium granules and the mixture is charged in to a leak tight tapered S.S. bomb reactor, which is initially lined with dry $\mathrm{CaF}_{2}$ powder by vibratory packing. The $\mathrm{CaF}_{2}$ lining serves for heat insulation and containment of the molten uranium. The calciothermic reduction is triggered - in an argon atmosphere-by electrically igniting a magnesium ribbon embedded at the top of the charge. The reaction is instantaneous, spreads rapidly through the mass, and the resulting liquid uranium droplets coalesce and collect at the bottom, forming a massive solid ingot on cooling.

A reduction route employing indigenous magnesium in place of imported calcium has been developed on a pilot plant scale is due to be adopted in the plant's expansion.

The calciothermic route described for uranium is applicable to the production of thorium and plutonium metals also.

The production of metals by the isothermal Kroll type reduction is exemplified by the magnesium reduction of zirconium tetrachloride. The process that has been tested on pilot plant scale at Trombay and adopted for tonnage production at the Nuclear Fuel Complex, Hyderabad is described below.

The reactor employs a specially designed S.S. retort and a three-zone furnace system for carrying out the reduction reaction. Zirconium tetrachloride and clean magnesium pigs are loaded in separate containers in the retort. After in situ purification of the chloride by pumping out the voltalite impurities at $300^{\circ} \mathrm{C}$, the magnesium temperature is raised to above its melting point (to $850^{\circ} \mathrm{C}$ ) and the chloride distilled in a controlled manner to react at the surface of molten magnesium. At the end of the reduction the excess magnesium and $\mathrm{MgCl}_{2}$ are separated from the resulting zirconium sponge by pyrovacuum distillation in another heavy-walled retort capable of evacuation down to 
$<1$ micron at $900^{\circ} \mathrm{C}$, the inconel retort is heated to $900^{\circ} \mathrm{C}$ using an evacuated bell-type furnace.

Similar reduction and pyrovacuum distillation equipment are suitable for production of titanium, thorium and hafnium metals.

For the production of tantalum powder from $\mathrm{K}_{2} \mathrm{TaF}_{7}$, a liquid-liquid reactor technique was developed at Trombay. Filtered high purity liquid sodium is continuously metered under argon cover on to the stirred mass of molten $\mathrm{K}_{2} \mathrm{TaF}_{7}$ and $\mathrm{NaCl}$ kept at $800-900^{\circ} \mathrm{C}$ in an inconel alloy 600 reactor. The tantalum metal powder is recovered from the reduced mass after leaching out the by-product fluorides with a series of aqueous reagents. This effort has extended to setting up of a production plant at NFC.

Calcium metal is unsuitable for the reduction of beryllium fluoride due to the formation of highly stable $\mathrm{CaBe}_{13}$. Beryllium metal is produced in the form of pebbles by the magnesium reduction of $\mathrm{BeF}_{2}$ in a graphite crucible in an induction furnace at $1100-1400^{\circ} \mathrm{C}$. The metal pebbles owing to their lightness float to the surface of the slag. The beryllium pilot plant at Vashi, New Bombay is designed for the production of the metal and its alloys to meet indigenous requirement.

\section{Reduction of oxides}

The area of oxide reduction processes has been extensively investigated for producing a number of rare metals. The oxides are characterised by their good stability, they are easily prepared and are often the economically attractive intermediates in metal production processes. As specific examples of the advances at Trombay, reference may be made of fairly large scale production processes operated for preparation of zirconium, hafnium and thorium metal powders through calciothermic reduction of their respective oxides. Another notable advance has been in the aluminothermic reduction technology applied with great ingenuity in the preparation of niobium, tantalum, vanadium and molybdenum.

A metallothermic reduction process that does not generate excess heat and thereby avoids the growth or sintering of reduced metal particles is highly conductive to metal powder preparation. Calcium reduction of zirconium dioxide at $900^{\circ} \mathrm{C}$ generates only around $43 \mathrm{kcals}$ per $\mathrm{g}$ mole of oxide. Further, the reduction is carried out in the presence of a heat sink like $\mathrm{CaCl}_{2}$, very fine metal powder (predominantly 3 micron size) results dispersed in a matrix of $\mathrm{CaO}$ and $\mathrm{CaCl}_{2}$. The metal powder is recovered from the reduced mass by careful aqueous leaching and drying. This technique has led to the establishment of a production facility for 1 ton $\mathrm{Zr}$ powder per annum at NFC.

Calciothermic reduction has also been investigated in detail for the preparation of hafnium, thorium, niobium and tantalum metal powders from their oxides. The process essentially consists of mixing the charge of calcium metal granules, metal oxide and calcium chloride heat sink in proper proportions and soaking it at the reduction temperature $\left(950-1000^{\circ} \mathrm{C}\right)$ in flowing argon atmosphere, for sufficient time; the reduced mass is subsequently leached with dilute acids.

Unlike the static bed reduction described above, in a bomb process, highly exothermic reactions are conducted to prepare high melting metals in their consolidated form. To achieve this objective in reactions releasing inadequate heat, there are various means. 
These include: (i) preheating to ignition, (ii) additives acting as thermal boosters, and (iii) combination of both.

The best reductant for the purposes just outlined is aluminium. The aluminothermic reduction may be described as combustion of aluminium to its oxide-the oxygen being released from the metal oxide. The reactions are carried out in an open vessel lined with refractory. The reactants at room temperature are mixed and charged and the charge is primed locally by means of an electric fuse embedded in the charge. In preheating to ignition, the entire charge is set to fire and the reaction is under near adiabatic conditions. The aluminothermic reduction, essentially a non-furnace process, proceeds rapidly to completion, but several hours of cooling is allowed before the contents are taken out. The metal if showing some slag adherence is cleaned by manual chipping.

A flowsheet, based on the aluminothermic reduction, for the production of niobium metal has been chosen for setting up of a plant at NFC.

Carbothermic reduction to produce refractory metals has become a reality only with the advancement in the regime of vacuum technology. The reactions are performed in a high temperature-high vacuum induction furnace where the pelletised oxide-carbon or carbide-oxide charge is reacted in the solid state to yield carbide or metal. A precise control of charge composition and the reaction conditions is very essential for obtaining pure metals having low residual carbon and oxygen contents. Adopting this process, complete flowsheets have been developed at the Metallurgy Division, BARC for the production of reactor grade niobium and capacitor grade tantalum metals.

\section{Electrolytic reduction}

For electrowinning of the reactive metals, only fused salt systems operating in an inert atmosphere have been found suitable.

Molten salt electrowinning processes for the preparation of refractory metals, particularly tantalum and titanium and rare earths like misch metal and cesium have been extensively investigated at Trombay. The metal compound (chloride, fluoride or oxide) is dissolved in a low melting eutectic salt mix ture composed of two or more alkali or alkaline earth chlorides or fluorides. During electrolysis, the high melting rare metals are obtained as adherent dendrite deposits on the cathode (which is kept suspended in the fused salt) or alternatively if the adherence characteristics are poor, the metal is generated in the form of powder, in which case the cell itself is used as the cathode (and the anode is kept suspended).

Tantalum and titanium have been electrodeposited in the dendritic and sponge form by electrolysing $\mathrm{KCl}-\mathrm{NaCl}$ melt containing respectively potassium tantalum fluoride and titanium chloride as functional salt. While for tantalum a centrally suspended metallic rod has been used as cathode, for titanium a perforated metallic basket served as the cathode. Such electrode arrangement for multivalent titanium has been found essential to separate the catholyte and anolyte.

In the pilot plant work on electrowinning of titanium, a 1000 amp internally heated inert atmosphere electrolytic cell has been used to standardise the parameters. The metals belonging to the rare earth group have been electrodeposited from all-chloride electrolytes. 


\section{Consolidation and purification of rare metals}

The primary sponge metals and metal powders are required to be consolidated by melting or sintering prior to conversion to mill products. In some cases the melting or sintering operation refines the metal to an extent.

The tolerable limits of impurities in rare metals are quite low. All the properties which make these metals unique in comparison with other common metals are drastically impaired even by low levels of metallic and interstitial impurities. Therefore, great care and special techniques are employed in the refining operation as summarised in figure 13.

Most of the purification methods for rare metals involve high temperature and vacuum. The purification methods available for the rare metals include (i) vacuum melting, (ii) iodide refining, (iii) zone melting, and (iv) molten salt electrorefining.

Except the metals uranium and beryllium which are consolidated and to some extent refined by vacuum induction melting and casting, majority of the rare metals are consolidated and refined by arc and electron beam melting procedures. In both these methods, crucible contamination is eliminated by carrying out the meltings in watercooled copper crucibles.

In vacuum arc melting, the heat is generated on the surface of the molten metal by the application of a low voltage high current electric arc from an electrode which may be either consumable or nonconsumable. While nonconsumable method is suitable for consolidation of metals, no appreciable purification is achievable on account of the low vacuum involved. On the other hand, in the consumable arc melting, the material to be melted is preformed into an electrode which is progressively consumed during melting. The process has the advantage of operating under higher vacuum $\left(10^{-2}\right.$ to $10^{-3}$ torr $)$ without contamination from electrode material and finds widespread use in the consolidation of rare metals. Facilities available at Trombay allow melting of 4 to 6 in. dia ingots of zirconium and titanium and at NFC metal ingots upto $12 \mathrm{in}$. dia can be cast.

Electron beam melting furnaces operate in high vacuum and provide high degree of super heat in the melt region and thus enable much greater refining than that possible with arc furnaces. In electron beam melting, the specimen is heated by subjecting it to

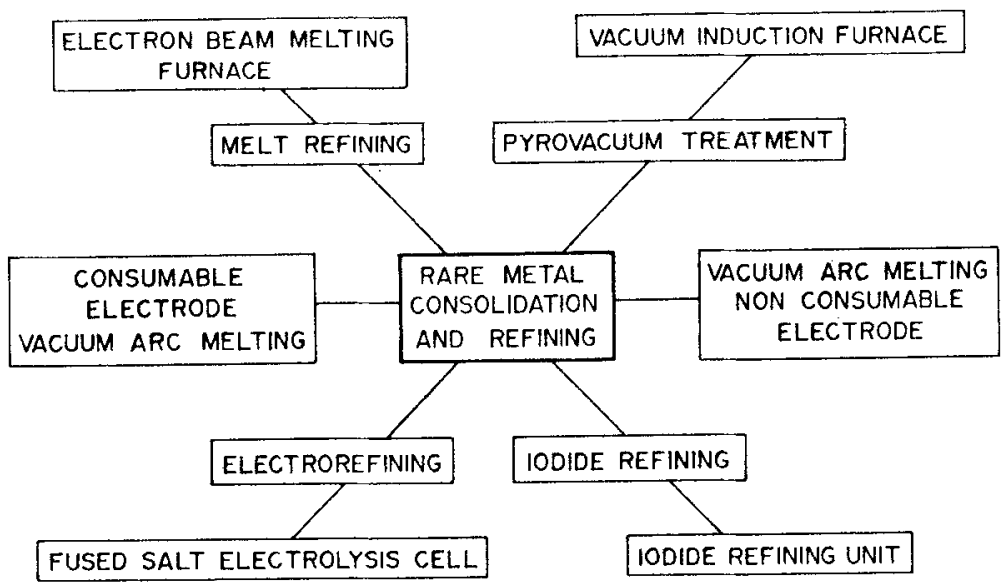

Figure 13. Techniques for consolidation and refining of rare metals. 
bombardment by a beam of high energy electrons under a vacuum better than $10^{-4}$ torr. Electron beam melting has, in fact, played a prominent role in its application to consolidation and purification of primary metals with widely different production history, and to preparation of metals with their finished purities meeting specific application requirements. Electron beam melting is effective and extensively used particularly in the production flowsheets of niobium and tantalum metals.

The reactions and processes that take place during vacuum melting and result in purification include (i) distillation of volatile impurities, (ii) vaporization of suboxides, (iii) carbon deoxidation, and (iv) vacuum degassing.

While vacuum melting is very effective in the purification of refractory metals it is not so with reactive rare metals like titanium, zirconium and hafnium. The so-called iodide refining has been found to be very effective in the refining of these metals.

Iodide refining, also known as the Van Arkel de Boer process, is based on the reversibility of a reaction between a metal and iodine. Purification of zirconium by this process has been studied extensively in the Metallurgy Division, BARC. The process is carried out in an evacuated inconel 600 vessel along the axis of which a high purity zirconium wire is aligned and electrically heated to $1300^{\circ} \mathrm{C}$. The crude zirconium sponge is stacked inside the vessel in the annular space between the vessel wall and a concentric screen. Iodine required for the process is sublimed into the evacuated vessel. The vessel is externally heated to $250-400^{\circ} \mathrm{C}$ to form volatile $\mathrm{ZrI}_{4}$ by reaction between zirconium sponge and iodine. The iodide vapours decompose on the surface of the high temperature zirconium filament resulting in a deposit of pure metal on it. The iodine vapours simultaneously liberated travel back for further reaction with the crude sponge.

A decomposition assembly developed at Metallurgy Division, BARC has been growing kilogram quantities of high purity crystal bars of zirconium, titanium and hafnium.

Zone melting is essentially a purification process by repeated crystallization from the melt. In practice two liquid-solid interfaces are produced for distribution of impurities by causing a relatively small molten zone to transverse the length of the bar of the charge. Many repetitions of the process lead to considerable purification even in cases where the distribution coefficient is close to unity. The impurities more soluble in the solid concentrate in the starting end.

It has been possible to produce kg quantities of metals such as $\mathrm{Bi}, \mathrm{Sb}, \mathrm{Sn}$ and $\mathrm{Cd}$ in their ultra-pure form for use in the semiconductor industry with zone refiners designed and fabricated at Trombay. A larger semi-automatic zone refiner is turning out ultrapure materials at NFC.

Zone refining in vacuum combines the benefits of conventional zone refining in a protective atmosphere, vacuum degassing and selective distribution of impurities. For refining of refractory metals an electron beam floating zone melting unit has been fabricated and used at the Metallurgy Division.

Electrorefining, next to electrowinning of metals is the most important aspect of fused salt electrolysis. While in electrowinning graphite has been found to be the most popular and inexpensive anode material, electrorefining cells essentially employ impure metal as the anode. The metal is crushed to suitable size and spread over the crucible bottom or packed in the annular space between the crucible and a perforated graphite screen to expose a large anode area. Molybdenum is the best reported cathode material in electrorefining. Iron has been used for vanadium electrorefining.

Molten salt electrorefining technique has been perfected for the preparation of high 
purity metals like niobium, tantalum, vanadium, molybdenum and chromium from their aluminothermically reduced alloy form. More recently electrorefining technique has been proved to be an effective mode for purification of calcium reduced hafnium. It has been possible to apply electrorefining for metal values of zircaloy scrap, and offgrade titanium sponge. Such purification technique has been found suitable not only for clean scrap but also for scraps contaminated with other metals and alloys which cannot be directly re-used in conventional remelting. Thus of all the refining methods applicable to rare metals, electrorefining stands out to be the most powerful technique with a wide range of refining capabilities.

\section{Thermodynamics in rare metals extraction}

In the development of process metallurgy of rare metals, the role of basic research particularly thermodynamic investigations has been very significant. Thermodynamic data have come to the rescue in many situations either during the choice of process parameters or in explaining many of the system behaviours. Though the involvement of thermodynamic analysis is very extensive and pervades almost all stages of rare metals reduction, refining and service, investigations concerning the vapour pressure and vaporization behaviours at elevated temperatures; solid solubility and phase diagram data have particularly been the main thrust areas for data collection and utilization. Investigations on metal-crucible interaction behaviours and decomposition processes can be cited for some of the direct application areas for thermodynamic data.

At the Extractive Metallurgy Section, several actual processes have been developed based solely on the available thermodynamic data of the system concerned. While it is impossible to carbothermically reduce zirconium and hafnium oxides, the important master alloys zirconium-niobium and hafnium-tantalum have been obtained by a carbothermic reduction process consisting of reduction of niobium pentoxide with zirconium carbide or tantalum pentoxide with hafnium carbide respectively. This scheme of reduction was worked out from the theoretical considerations of the thermodynamic stabilities of carbides and oxides and the stabilities and vaporization behaviours of the suboxides of zirconium, hafnium, niobium and tantalum. Another example of major flow sheet development that was visualised from the thermodynamic properties of the concerned compounds, is found in a recently concluded investigation on the preparation of pure niobium and tantalum through their nitride intermediates. The comparative stability of niobium and tantalum nitrides with respect to the niobium and tantalum carbides at moderate temperatures and the complete instability of these nitrides (in contrast to the persistent stability of the carbides) at higher temperatures and vacuum conditions has made it possible to obtain the pure metals starting from the oxides by a single sequential step consisting of (i) carbothermic reduction of niobium or tantalum pentoxide under a nitrogen atmosphere at $1500-1600^{\circ} \mathrm{C}$ to obtain the corresponding nitride and (ii) pyrovacuum decomposition of the nitride, at 2000-2100 ${ }^{\circ} \mathrm{C}$ under $10^{-4}$ torr, to pure metal.

In addition to the above mentioned types of applications, thermodynamic analyses have extensively been employed in various pyrovacuum refining operations, leading to successful process operation, improved yield, reduction in number of processing steps and similar improvements. 


\section{Evaluation of rare metals}

The development of flow sheets for the extraction of high pure rare metals has depended to a great extent on the parallel development and availability of powerful analytical techniques which enabled the evaluation of products at various stages. Special efforts are required particularly when the impurity concentrations are vanishingly low. The important analysis techniques applied in the rare metals evaluation are diagramatically presented in figure 14 .

\section{Concluding remarks}

In the evolution and developments of flowsheets for rare metal extraction, the R\&D effort has had many facets as summarised in figure 15 .

As compared with the historical development of the process metallurgy of common metals, there has been a much more systematic and scientific approach to the chemical metallurgy of rare metals. This has been possible through many advances in analytical chemistry, physical chemistry, instrument and equipment development, physical and chemical engineering which have provided new technologies, and also through entirely

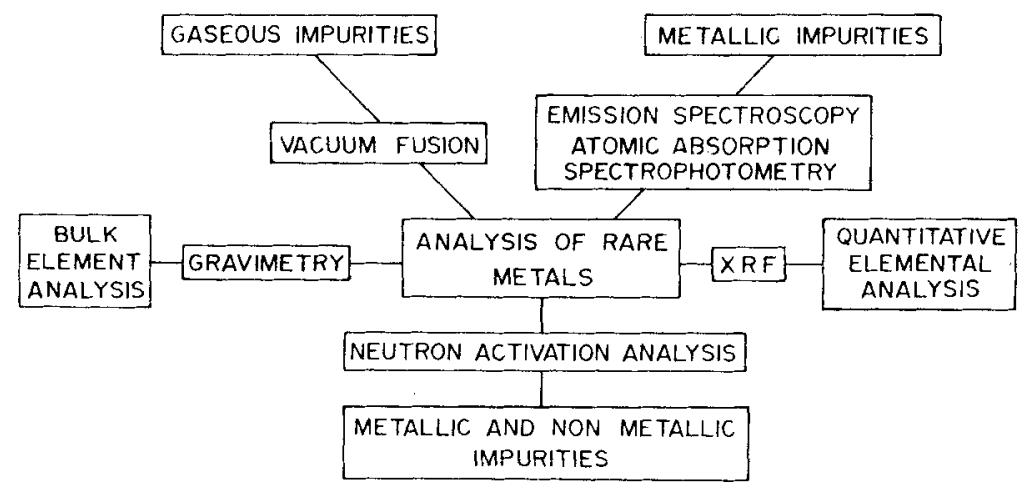

Figure 14. Evaluation of rare metals.

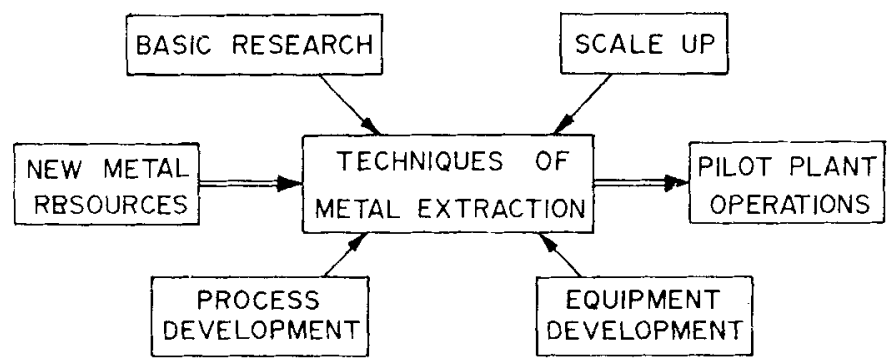

Figure 15. Development of extractive processes for rare metals. 
novel metallurgical engineering designs. Our basic understanding of chemical and metallurgical systems, phenomena and reactions has also vastly improved through progress in theory and experiment in rare metals extraction.

Although process metallurgy of rare metals has grown into a powerful, mature and composite discipline, a good deal of scope for further R\&D efforts still remains. Specifically one can mention fertile areas like pyrochemical counter current fused salt reactors for achieving separation of zirconium from hafnium, adoption of fluidised bed reactor for gas solid reactions, employment of plasma processing techniques for mineral beneficiation and refractory metal reduction-all of which deserve detailed study.

An interesting aspect of development of processes for rare metals extraction has been that many of these new techniques have important relevance to the common metals processing also. Special mention may be made of the prospects of solvent extraction processes in the copper and nickel industries and ion exchange in certain by-product metal recovery processes from effluent solutions, chlorination processing of complex sulphide ores, and vacuum melt refining.

Growth, development and maturity in operating practice have marked the evolution of various process options taken for investigations at BARC. Whenever possible and desirable, the process development was pursued through the various stages and led to its logical conclusion-setting up of operating production facilities. An important aspect that has marked this style of evolution is that the person or persons who have conceived, tested and developed the idea and the process have also been given the opportunity of setting up the plant and running it. This has made further growth and expansion of the plant feasible and easier. In certain cases, the nature of the project is more suited for effecting a transfer of technology to organizations outside the department. In this context, it is well worth noting that the technology of aluminothermic reduction of ferroalloys viz., ferrovanadium, ferroniobium, ferromolybdenum and ferrotungsten-so well mastered at the Extractive Metallurgy Section has been transferred to industries in Madhya Pradesh. In another instance, based on the flowsheet and technology developed at the Extractive Metallurgy Section, a demonstration plant for the processing of casseterite concentrates is being set up at Raipur by Metallurgy Division jointly with the Madhya Pradesh State Mining Corporation. One would appreciate that such instances are tantamount to bringing the advanced research facilities and expertise within the reach of a wider section of industries and to the greater service for our country's mainstream industrial activity.

The foresight and imagination in the organisation, of the successive stages of the programme, has paid good dividends; strong and comprehensive base that we now have in rare metals processing industry should inspire confidence for further growth and diversification of this technology in our country.

\section{Acknowledgement}

The authors appreciate the manysided help rendered by Shri $\mathrm{N}$ Krishnamurthy, Metallurgy Division, BARC in the preparation of this paper. Contributions from the various research groups, particularly from the Metallurgy, Chemistry, Chemical Engineering and Ore Extraction Divisions of BARC, Bombay and the Nuclear Fuel Complex, Hyderabad have actually provided the basic theme of this present article. 


\section{Representative bibliography}

Damodaran A D, Deshpande S G, Majumdar A A, Sastri M S, Jena P K, Bose D K, Chandra S, Gupta C K and Taneja A K 1970 Proc. Indian Nat. Sci. Acad. A36 306

Gupta C K 1972 in Recent developments in metallurgical science and technology, Proc. IIM Symp. on Process Metallurgy, New Delhi p. 515

Gupta C K 1984 Extractive metallurgy of niobium, tantalum and vanadium Int. Metals Rev. (Under Publication)

Gupta C K and Sundaram C V 1973 The Banaras Metall. 5190

Krishnamurthy N, Venkataramani R, Garg S P and Sundaram C V 1981 in Trends in refractory metals, hard metals, and special materials and their technology, Proc. Tenth Plansee Seminar Metallwerk Plansee, Reutte, Vol. 1, p 263

Mukherjee T K, Bose D K and Gupta C K 1972 in DAE Symp. High. Temp. Mat. Hyderabad, p. 221

Mukherjee T K and Gupta C K 1976 Trans. SAEST 11127

Mukherjee T K, Garg S P, Gupta C K, Sundaram C V, Taneja A K and Damodaran A D 1978 in Electron beam melting and welding, Proc. Int. Conf., Avignon

Proc. INSA-BARC Winter School on Chemistry and Metallurgy of Rare Metal Extraction, BARC (Jan 1975)

Saratchandran N and Sundaram C V 1970 in DAE Materials Science Symp. NAL, Bangalore, p. 251

Subramanyam R B, Saratchandran N and Sundaram C V 1973 J. Sci. Ind. Res. 32672

Subba Rao K S, Sharma B P, Paul C M and Sundaram C V 1977 Beryllium development programme in India, Conf. Preprints: Beryllium, Fourth Int. Conf. on Beryllium, The Metals Society, London

Sundaram C V, Garg S P and Sehra J C 1979 in Metal sciences-The emerging frontiers, Proc. Int. Conf., The Indian Institute of Metals

Sundaram C V and Sharma B P 1972 in Recent developments in metallurgical science and technology, Proc. IIM Symp. on Process Metallurgy, New Delhi, p. 479

Sundaram C V and Suri A K 1976 in High temperature reactions and processes Proc. KREC, Suratkal p. 27 